\title{
Technical Note: The application of an improved gas and aerosol collector for ambient air pollutants in China
}

\author{
H.-B. Dong ${ }^{1,2,3}$, L.-M. Zeng ${ }^{2}$, M. Hu ${ }^{2}$, Y.-S. Wu ${ }^{2}$, Y.-H. Zhang ${ }^{2}$, J. Slanina ${ }^{2}$, M. Zheng ${ }^{2}$, Z.-F. Wang ${ }^{1}$, and R. Jansen ${ }^{2,4}$ \\ ${ }^{1}$ State Key Laboratory of Atmospheric Boundary Layer Physics and Atmospheric Chemistry, \\ Institute of Atmospheric Physics, Chinese Academy of Sciences, Beijing, China \\ ${ }^{2}$ State Key Joint Laboratory of Environmental Simulation and Pollution Control, \\ College of Environmental Sciences and Engineering, Peking University, Beijing, China \\ ${ }^{3}$ Graduate University of Chinese Academy of Sciences, Beijing, China \\ ${ }^{4}$ Energy Research Centre of the Netherlands (ECN), Westerduinweg 3, Building 04, 1755 ZG Petten, The Netherlands
}

Correspondence to: L.-M. Zeng (lmzeng@pku.edu.cn) and M. Hu (minhu@pku.edu.cn)

Received: 7 March 2012 - Published in Atmos. Chem. Phys. Discuss.: 20 March 2012

Revised: 25 October 2012 - Accepted: 26 October 2012 - Published: 12 November 2012

\begin{abstract}
An improved Gas and Aerosol Collector (GAC) equipped with a newly designed aerosol collector and a set of dull-polished wet annular denuder (WAD) was developed based on a Steam Jet Aerosol Collector (SJAC) sampler. Combined with Ion Chromatography (IC) the new sampler performed well in laboratory tests with high collection efficiencies for $\mathrm{SO}_{2}$ (above $98 \%$ ) and particulate sulfate (as high as $99.5 \%)$. An inter-comparison between the GAC-IC system and the filter-pack method was performed and the results indicated that the GAC-IC system could supply reliable particulate sulfate, nitrate, chloride, and ammonium data in field measurement with a much wider range of ambient concentrations. When applied in two major field campaigns (rural and coastal sites) in China, the GAC-IC system provided highquality data in ambient conditions even under high loadings of pollutants. Its measurements were highly correlated with data by other commercial instruments such as the $\mathrm{SO}_{2}$ analyzer (43c, Thermo-Fisher, USA; $R^{2}$ as 0.96 ), the HONO analyzer (LOPAP, Germany; $R^{2}$ as 0.91 for samples from 15:00 to 07:00), a filter sampler (Tianhong, China; $R^{2}$ as 0.86 for $\mathrm{SO}_{4}^{2-}$ ), and Aerosol Mass Spectrometer (AMS, Aerodyne, USA; $R^{2}$ above 0.77 for major species) over a wide range of concentrations. Through the application of the GAC-IC system, it was identified that $70 \%$ of chloride and nitrate by the filter method could be lost during daytime sampling due to high temperature in the rural site of Kaiping. In Changdao field campaign (coastal site), though a particle dryer was applied, its drying efficiency was not well considered for
\end{abstract}

the collection efficiency of AMS seemed still interfered a bit by local high relative humidity. If the inter-comparison was done with relative humidity below $50 \%$, the correlations ranged from 0.81 to 0.94 for major species. Through laboratory and field studies, this instrument is proved particularly useful in future intensive campaigns or long-term monitoring stations to study various environmental issues such as secondary aerosol and haze formation, as well as climate change.

\section{Introduction}

To study the sources, formation processes, and fate of pollutants in the atmosphere, it is very important to develop fast and advanced instruments to accurately and quantitatively characterize concentration and composition of both aerosol and trace gases, which exhibit distinct spatial and temporal variations. Gases species such as $\mathrm{SO}_{2}, \mathrm{NO}_{2}$ and $\mathrm{NH}_{3}$ are important precursors of secondary inorganic components in aerosol including sulfate, nitrate, and ammonium. These water-soluble components contribute about one-third of particulate matter mass in typical urban areas (Andreae et al., 2008). Besides their abundance in particulate matter, the environmental impacts are of particular concerns especially their role in aerosol acidification and the earth's radiation balance by directly scattering incoming solar radiation and indirectly by altering cloud properties as particles can 
serve as cloud condensation nuclei (Hillamo et al., 1998; Andrews et al., 2000; Chow et al., 2006; Seinfeld and Pandis, 2006). Therefore, their formation mechanisms and sources have been widely and actively studied through measuring these components and their precursor gases in the ambient air along with meteorological measurements ( $\mathrm{Hu}$ et al., 2002; Yao et al., 2002; Khoder, 2002). As products of particle formation, growth and processing in the atmosphere, watersoluble ions usually can be used as good indicators of chemical reactions occurring on the surface of particles (Wang et al., 2006).

Trebs et al. (2004) have summarized the most common online and off-line methods for measuring inorganic gaseous and particulate species in ambient air. Filter sampling is a traditional method for measuring particulate species, and is still being actively used in quite a lot of field campaigns nowadays. However, there are well-known disadvantages associated with this method such as underestimation of volatile components (semi-volatile organics and ammonium nitrate), various positive and negative artifacts, labor intensive and so on (Chow, 1995; Keuken et al., 1989; Niessner and Klockow, 1980; Slanina et al., 2001). An efficient way to reduce the artifacts due to filter sampling and storage and to meet the need for acquiring high time-resolution aerosol composition information is to develop continuous or semi-continuous airmonitoring techniques and instruments.

On-line measurements of aerosol ions can be achieved by wet and dry methods. For the wet method, two representative instruments are the Steam Jet Aerosol Collector (SJAC) system developed by Prof. Khlystov of Netherlands Energy Research Foundation (ECN) (Khlystov et al., 1995) and the Particle-Into-Liquid Sampler (PILS) system developed by Prof. Weber at Georgia Institute of Technology (Weber et al., 2001, 2003; Orsini et al., 2003). The difference between PILS and SJAC is that particles are first grown with steam, then impacted and collected in PILS system whereas SJAC applies a cyclone to collect grown particles. Additionally, gaseous water soluble species are also measured by SJAC system. Only aerosol components are measured in PILS system.

The dry technique is also applied nowadays to measure aerosol ions including aerosol mass spectrometer (AMS) (Jayne et al., 2000; DeCarlo et al., 2006) and R\&P 8400S/N (Drewnick et al., 2003; Stolzenburg and Hering, 2000). For AMS, particle beam, formed by the lens, passes a skimmer and a chopper and impacts onto a heater, followed by flash vaporization and electron impact ionization. The ions are analyzed by quadrupole mass spectrometer. It provides high time resolution and abundant chemical composition information. R\&P $8400 \mathrm{~S} / \mathrm{N}$ only measures sulfate or nitrate which are flash-evaporated in the instrument and then $\mathrm{SO}_{2}$ and $\mathrm{NO}$ produced during vaporization are determined.

Lots of inter-comparisons for semi-continuous instruments have been studied; however, these studies were mainly executed under clean environment with low sulfate and ni- trate concentration (Drewnick et al., 2003; Homolya et al., 2005; Makkonen et al., 2012). For wet technique, problems including lower sulfate measurement in areas with high sulfate loading, higher sulfate measurement under high $\mathrm{SO}_{2}$ environment, peristaltic pumps tube broken up easily, etc., are noteworthy. Based on measurement by a semi-continuous instrument, Wu and Wang (2007) have reported that sulfate readings tend to be lower when ambient sulfate is above $20 \mu \mathrm{g} \mathrm{m}^{-3}$ and to be higher when $\mathrm{SO}_{2}$ concentration is very high (>30 ppb). By using alkaline solution as high as $5 \mathrm{mM}$ and changing the flow rate from 3 to $21 \mathrm{~min}^{-1}$, the performance of that system has been improved significantly (Nie et al., 2010). The problem of lower sulfate readings under high sulfate loading can be also concluded from the study by Drewnick (2003) in New York.

In the early 2000s, a SJAC sampler was introduced into Peking University from ECN and applied in air quality study in China. Connected with ion chromatography (IC) from Dionex Company (ICS-90), this system has been used in many field campaigns in Beijing and Guangzhou over these years (Hu et al., 2002; Su et al., 2008a, b). However, the problems of positive bias due to high $\mathrm{SO}_{2}$, negative bias at high sulfate loadings and peristaltic pumps tube broken up easily also occur in these applications. In this study, we aim to modify and improve the SJAC sampler to extend its application in special environment especially heavily polluted areas such as mega-cities in China. The Gas and Aerosol Collector (GAC) is developed for such a purpose. The detailed improvements of GAC are presented in this study and its performance and efficiency are carefully evaluated by comparing with other techniques and measurements. The combination of GAC with Ion Chromatography (IC) can provide online measurements of concentration of water soluble gaseous and aerosol species. In this study, the application of an improved GAC-IC system in a few field campaigns is presented.

\section{Methodology}

\subsection{The Gas and Aerosol Collector (GAC)}

The most important improvement of GAC is the newly designed aerosol collector, where particles can grow under supersaturated conditions. As shown in Fig. 1, it has three glass components including an aerosol mixing chamber $(100 \mathrm{ml})$, a coil aerosol cooler and an impactor aerosol trapper (contain cold water bath). Aerosol samples go into the collector through the "stream in" port, mixed with steam generated by ultra pure water $(18.2 \mathrm{M} \Omega)$ at a flow rate of $1.0-1.2 \mathrm{ml} \mathrm{min}^{-1}$ under constant temperature of $120^{\circ} \mathrm{C}$. The stream goes through the aerosol chamber and the coil aerosol cooler where particles grow to droplets and finally collected by the impactor aerosol trapper (contain cold water bath). The collected water sample is pumped out the trapper from the "sample out" port and the stream goes out from the "air 


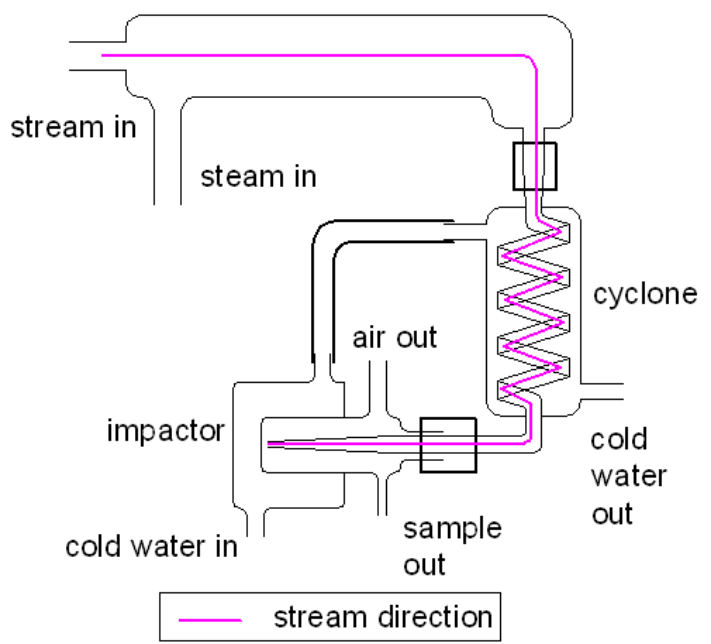

Fig. 1. The newly designed aerosol collector used in the GAC to enhance the aerosol collection efficiency.

out" port. There is circulating cooling water (around $10^{\circ} \mathrm{C}$ ) going through the outer shell of the coil aerosol cooler and the impactor aerosol trapper which accelerates the growth and condensation of droplets by lower the water saturation vapor pressure and increasing the degree of water saturation $(\mathrm{RH})$. The introduction of circulating cooling water and the impactor aerosol trapper were the essential difference between GAC and SJAC for the aerosol collector part which ensures aerosol fully collected under high loadings.

Circulating water is pumped through a chamber made from red copper outside of which two pieces of semiconductor chilling plate, cooling fin and cooling fan are assembled together to achieve the cooling purpose. Through the red copper chamber, the circulating water can be cooled down to around $10^{\circ} \mathrm{C}$.

The wet annular denuder (WAD) used in the GAC is the same as that in the SJAC, but the inner-surface is dull polished. This change improved the hydrophilic performance of the denuder and enhanced the scavenging capacity of gaseous species for water film formed on the inner-surface of the denuder is quite uniform. The WAD is continuously rotated and the absorption solution can wet the inner surface. The absorption solution (usually ultra pure water or diluted alkaline solution) is pumped into the denuder by a micro pump (BIO-CHEM Fluidics, USA) at a flow rate of $1.0-1.2 \mathrm{ml} \mathrm{min}^{-1}$ and pumped out at the other side.

The GAC system developed in this study is schematically shown in Fig. 2. A cyclone with a cut-off size of 2.5 micrometer (URG, USA) will be installed before air pumped into the GAC at a flow rate of $16.71 \mathrm{~min}^{-1}$ under a flow controller which is periodically checked by a bubble flow meter (Sensidyne, USA). The stream goes through the WAD by a direction reverse with absorption solution flowing in the WAD. Gaseous species diffuse to the inner surface and are scavenged by the absorption solution. Particulate matter below

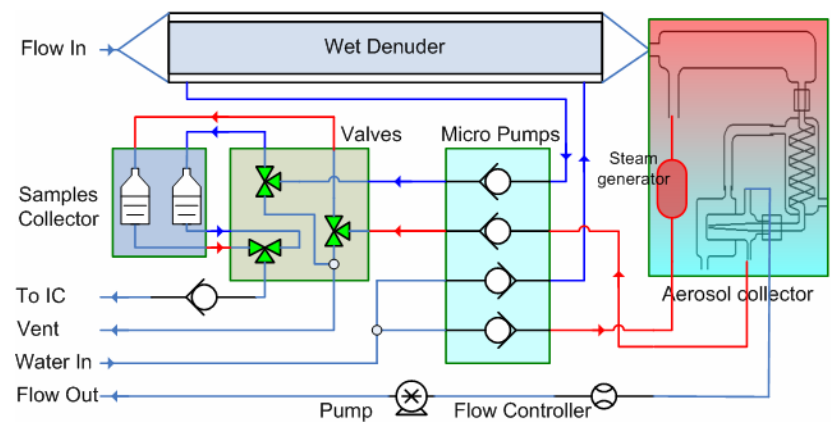

Fig. 2. Overview of the improved GAC sampler equipped with a newly designed aerosol collector.

2.5 micrometer $\left(\mathrm{PM}_{2.5}\right)$ passes through the denuder and enters into the aerosol collector. Both gaseous and aerosol samples are injected into two $30 \mathrm{ml}$ glass bottles being weighted by weighting transducers separately. Gaseous samples are collected into one bottle in the first $15 \mathrm{~min}$, and then aerosol samples are collected in the other bottle in the following $15 \mathrm{~min}$. Therefore, the time resolution for the $\mathrm{GAC}$ is $30 \mathrm{~min}$. The recorded weights of gaseous- and aerosol samples are used in the calculation of concentration of each species.

Two IC systems (ICS-90, Dionex, USA) are combined with the GAC sampler to quantify different gaseous and particulate species. One IC is equipped with a $4 \times 25 \mathrm{~mm}$ guard column (type IonPac AG 14) followed by a $4 \times 250 \mathrm{~mm}$ analytical column (type IonPac AS 14) with a mixture of $3.5 \mathrm{mM}$ $\mathrm{CO}_{3}^{2-}$ and $1.0 \mathrm{mM} \mathrm{HCO}_{3}^{-}$as eluent solution. The other IC is installed with a $4 \times 25 \mathrm{~mm}$ guard column (type IonPac CG 12) followed by a $4 \times 250 \mathrm{~mm}$ analytical column (type IonPac CS 12) with $20 \mathrm{mM}$ methanesulfonic acid as eluent solution. Both ICs were electronically suppressed to reduce the background signal. Samples were injected through $20 \mu \mathrm{l}$ loops of two ICs at a flow rate of $1.0 \mathrm{ml} \mathrm{min}{ }^{-1}$. During the period of sampling gaseous pollutants, the aerosol samples are automatically injected into two ICs, and then the concentrations of $\mathrm{HCl}, \mathrm{HONO}, \mathrm{HNO}_{3}, \mathrm{SO}_{2}, \mathrm{NH}_{3}$ in gaseous phase and $\mathrm{Cl}^{-}, \mathrm{NO}_{3}^{-}, \mathrm{SO}_{4}^{2-}, \mathrm{Na}^{+}, \mathrm{NH}_{4}^{+}, \mathrm{K}^{+}, \mathrm{Mg}^{2+}$ in aerosol phase can be calculated.

Additionally, Micro pumps (BIO-CHEM Fluidics, USA) are firstly introduced into such kind of samplers instead of injection pumps or peristaltic pumps (used in PILS and SJAC). They work in impulse mode with a constant flow rate about $20 \mu \mathrm{l}$ per pulse and only $1 / 16$ inch Teflon tube connected with no accessory easily worn out. The weighing transducers applied in the GAC allows recording the weight of each sample in order to accurately calculate concentrations of gaseous and aerosol species which is a much cheaper but convenient way. This improvement is particularly helpful to immediately identify errors in sampling or invalid samples based on the recorded data of weight.

Through careful integration and efficient improvement, the GAC sampler becomes much smaller than the SJAC. 
It is more suitable for transportation to be applied into field campaigns.

\subsection{The performance of GAC}

\subsubsection{Collection efficiency of $\mathrm{SO}_{2}$}

Both negative and positive artifacts occur when the WAD does not collect gases efficiently which can lead to underestimate of gaseous concentration. A less efficient denuder can result in overestimation of the signal of aerosol sample because soluble gases not captured by the WAD will dissolve in the steam environment of the aerosol collector.

Diffusion coefficient and solubility are two key factors for gas collection efficiency. The speed of gas diffusing to the surface of the WAD is primarily determined by the diffusion coefficient. Higher diffusion coefficients result in faster transport of gases. Among multiple gaseous species measured in this study $\left(\mathrm{SO}_{2}, \mathrm{HNO}_{3}, \mathrm{HONO}\right.$ and $\left.\mathrm{HCl}\right), \mathrm{SO}_{2}$ has a relatively lower diffusion coefficient and lower solubility in water. Therefore, if the WAD shows high collection efficiency for $\mathrm{SO}_{2}$, high collection efficiency should be expected for other gases as well (Simon and Dasgupta, 1993).

Zero air produced by a zero air source (Model 1001, Sabio, USA) was mixed with certificated standard $\mathrm{SO}_{2}$ gas from cylinder in a Dynamic Gas Calibrator (Model 146i, ThermoFisher, USA) which can provide stable $\mathrm{SO}_{2}$ gas flow with different concentrations by adjusting the mass flow controller in the instrument. A gas flow rate of $201 \mathrm{~min}^{-1}$ was produced where GAC sampled 16.71 into WAD per minute. The majority of the gas diffuses to surface of the denuder and is collected by the absorption solution and a small portion of $\mathrm{SO}_{2}$ may pass through the denuder and is then trapped by steam. If $G$ and $A$ stand for sulfur concentration of the solution collected by the denuder and steam respectively, the ratio of $G /(G+A)$ represents the collection efficiency of $\mathrm{SO}_{2}$.

Alkaline solution is normally used as the absorption solution in previous research due to its better absorption efficiency for $\mathrm{SO}_{2}$. However, $\mathrm{HONO}$, an important gas that is also collected and measured by the GAC, is likely produced under the presence of both $\mathrm{SO}_{2}$ and $\mathrm{NO}_{2}$, especially in alkaline solution (Spindler et al., 2003; Vecera and Dasgupta, 1991). In this study, three absorption solutions including ultra pure water, $25 \mu \mathrm{M}$ and $100 \mu \mathrm{M} \mathrm{Na}_{2} \mathrm{CO}_{3}$ solutions were tested for $\mathrm{SO}_{2}$ collection efficiency.

As seen from Fig. 3, collection efficiency higher than $98 \%$ was found when $\mathrm{Na}_{2} \mathrm{CO}_{3}$ solutions $(25 \mu \mathrm{M}$ and $100 \mu \mathrm{M})$ were used and such efficiency almost did not change when $\mathrm{SO}_{2}$ concentration increased up to $90 \mathrm{ppb}$. However, the efficiency decreased slightly when water was used as absorption solution (from $97.5 \%$ to $94 \%$ when $\mathrm{SO}_{2}$ concentration increased from 20 to $120 \mathrm{ppb}$ ). In fact, ambient $\mathrm{SO}_{2}$ concentrations in China are typically in the range of $20-100 \mathrm{ppb}$ with significant seasonal variations from summer to winter. When field campaigns are carried on, different absorption so-

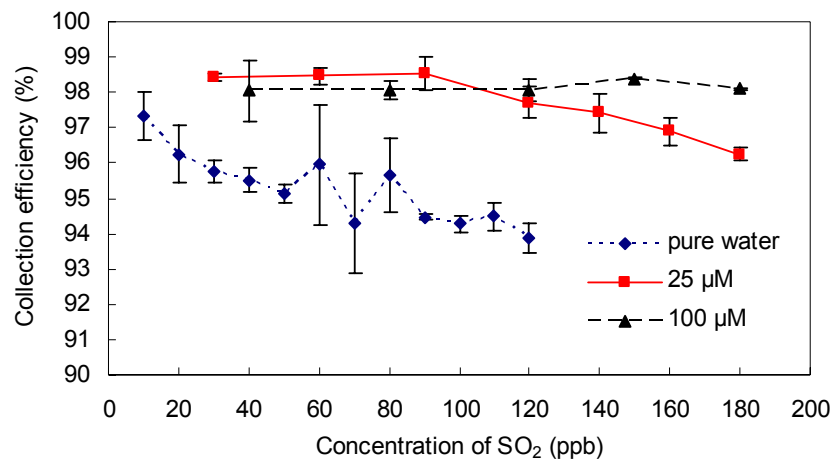

Fig. 3. Collection efficiencies of $\mathrm{SO}_{2}$ by the WAD used in the GAC for three solutions with standard deviation labeled.

lution can be chosen according to actual $\mathrm{SO}_{2}$ concentration in environment.

\subsubsection{Aerosol collection efficiency}

Particle loss due to non-isokinetic sampling also results in negative and positive artifacts. In the denuder, some ions that should not be present due to their low vapor pressure are sometimes observed, indicating that particle loss actually occurs when air passes through the denuder and thus leads to negative artifact.

Particles were generated to investigate (1) particle loss in the wet denuder and (2) the collection efficiency of the aerosol collector. We used poly-disperse aerosol to specifically test possible influence of particle concentration on collection efficiency (e.g. vapor depletion, etc.), because ambient aerosol in China is characterized by high particle number and mass concentrations compared to the levels often found in other locations.

Ammonium sulfate solution in different concentrations (from 0.5 to $25 \mathrm{mM}$ ) was prepared to generate particles with different physical properties. The size and number of the generated particles change when the concentration of the solution used for particle generation changes (see TSI Atomizer manual, Model 3097, TSI, USA). A constant low particle flow rate of $\sim 11 \mathrm{~min}^{-1}$ ( $2 \mathrm{psi}$ ) was mixed with a flow rate of $201 \mathrm{~min}^{-1}$ of zero air generated by a zero air source (Model 1001, Sabio, USA) and controlled by a mass flow controller in the Dynamic Gas Calibrator (Model 146i, Thermo-Fisher, USA). The zero air and generated particles were mixed in a 4.51 polypropylene mixing tank from where the GAC sampled continuously at a flow rate of $16.71 \mathrm{~min}^{-1}$. A Teflon filter (Whatman, UK) was connected following the aerosol collector in the GAC before air passing through the pump. The filter samples were extracted in the same way as introduced in Sect. 3.1.1.

A Scanning Mobility Particle Sizer (SMPS, Model 3936, TSI, USA) consisting of a Differential Mobility Analyzer (DMA, Model 3080L, TSI, USA) and a Condensation Particle Counter (CPC, Model 3775, TSI, USA) were connected 


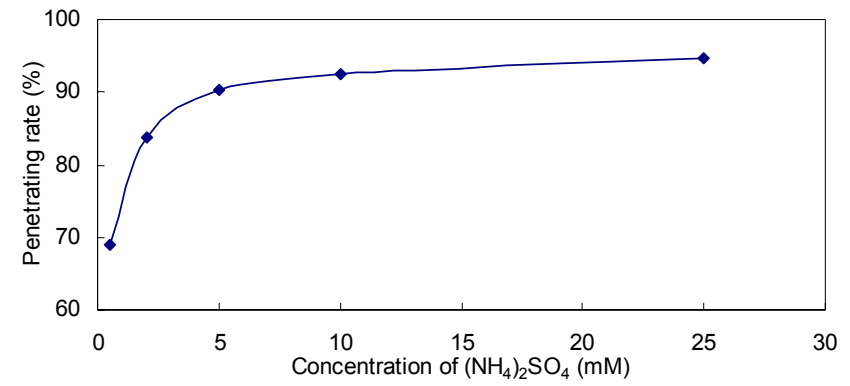

Fig. 4. Aerosol penetrating rate through the WAD versus $\left(\mathrm{NH}_{4}\right)_{2} \mathrm{SO}_{4}$ concentrations used for particles generation.

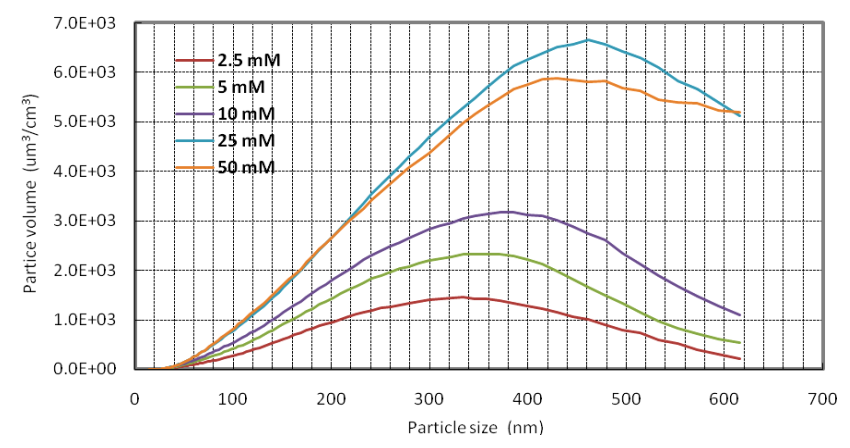

Fig. 5. Particle volume size distributions for different $\left(\mathrm{NH}_{4}\right)_{2} \mathrm{SO}_{4}$ concentration used for particles generation.

to the mixing tank to measure the number size concentration of generated particles. The flow rate of the DMA and CPC were 3 and $0.31 \mathrm{~min}^{-1}$ respectively and the particle size distribution was measured between 20 and $700 \mathrm{~nm}$ every $5 \mathrm{~min}$. The particle volume size distributions were shown in Fig. 5.

Three types of sulfate concentration were obtained from this system including $G$ (sulfate left in the denuder), $A$ (sulfate trapped by the aerosol collector) and $F$ (sulfate extracted from the filter). The ratio of $(A+F) /(G+A+F)$ and $A /(A+F)$ represent the percentage of aerosol penetrating the denuder and aerosol collection efficiency, respectively.

Figure 4 shows that the particle loss in the denuder is lower at higher concentrations of $\left(\mathrm{NH}_{4}\right)_{2} \mathrm{SO}_{4}$. When $\left(\mathrm{NH}_{4}\right)_{2} \mathrm{SO}_{4}$ concentration is greater than $5 \mathrm{mM}$, particle penetrating rate exceeds $90 \%$. The sulfate concentration detected in the WAD accounts for almost $15 \%$ of total sulfate when $\left(\mathrm{NH}_{4}\right)_{2} \mathrm{SO}_{4}$ concentration is $2.5 \mathrm{mM}$. We estimate from Fig. 5 that particles larger than $120-150 \mathrm{~nm}$ can pass through the denuder and get into the aerosol collector. Because of the small inertia, smaller particles, which dominate at lower concentrations of $\left(\mathrm{NH}_{4}\right)_{2} \mathrm{SO}_{4}$, are easily diffused and captured by the WAD, leading to lower penetration ratio. Although ultra fine particles $(<100 \mathrm{~nm})$ dominate the total particle number concentrations in urban areas, their contributions to total $\mathrm{PM}_{2.5}$ mass are negligible (Seinfeld and Pandis, 2006). In ambient atmosphere, most of the aerosol mass is due to the particles with a diameter larger than $500 \mathrm{~nm}$ and particle number con-

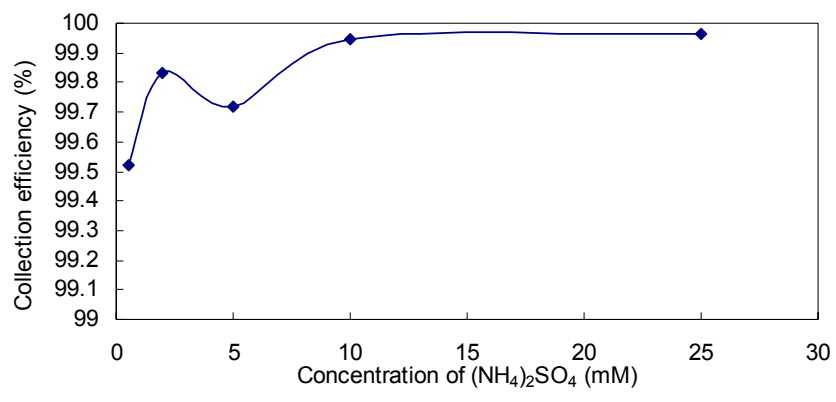

Fig. 6. Aerosol collection efficiency versus $\left(\mathrm{NH}_{4}\right)_{2} \mathrm{SO}_{4}$ concentrations used for particles generation.

centrations rarely reach as high as $10^{6} \mathrm{~cm}^{-3}$ in ambient atmosphere. So the performance of the GAC sampler is adequate for be applied in the ambient atmosphere to monitor gaseous and particulate air pollutants.

Figure 6 shows excellent collection efficiency (> 99.5\%) of the aerosol collector and it is independent of the concentration of $\left(\mathrm{NH}_{4}\right)_{2} \mathrm{SO}_{4}$ used. However there is still a trend of higher collection efficiency with the increase of $\left(\mathrm{NH}_{4}\right)_{2} \mathrm{SO}_{4}$ concentration. This result clearly demonstrates that the aerosol collector used in the GAC sampler has excellent collection efficiency and performance.

\subsubsection{Limit of detection (LOD)}

Limit of detection for each species (Table 1) was determined in the laboratory by sampling zero air generated from zero air source (Model 1001, Sabio, USA) continuously. The detection limit is defined as the background value adding three times the signal to noise ratio.

\subsubsection{GAC performance in aerosol measurement}

An inter-comparison between the GAC-IC system and the filter-pack method was performed with twenty-two sets of filter-pack samples collected from 23 to 30 July 2012. Filter sampling time for each set varied from 4 to $7 \mathrm{~h}$. A three-stage denuder (1st stage: carbon honeycomb, 2nd stage: $1 \%$ citric acid-impregnated honeycomb and 3rd stage: $1 \% \mathrm{NaCl}-$ impregnated honeycomb) was installed before filter holder to remove ambient gaseous species $\left(\mathrm{VOCs}, \mathrm{SO}_{2}, \mathrm{HNO}_{3}, \mathrm{HCl}\right.$ and $\mathrm{NH}_{3}$ ) and a three-stage filter-pack (1st stage: PTFE filter, 2nd stage: $0.2 \% \mathrm{Na}_{2} \mathrm{CO}_{3}$ - impregnated Whatman 41 filter and 3rd stage: $1 \%$ citric acid-impregnated Whatman 41 filter) was applied to collect the particulate nitrate, chloride and ammonium. The exposed filters were ultrasonically extracted by $10 \mathrm{ml}$ ultrapure water and analyzed by ICs (ICS2000 and ICS2500 from Dionex Company). Finally, the ambient concentrations of nitrate and chloride for filter measurement were calculated by the sum of their levels in the first and the second stage of filter-pack; while the sum of ammonium from the first and the third stage represented particulate ammonium for filter measurement. 
Table 1. LOD of Each Species GAC-IC measured.

\begin{tabular}{lrrrrrr}
\hline Gaseous phase & $\mathrm{HF}$ & $\mathrm{HCl}$ & $\mathrm{HONO}$ & $\mathrm{HNO}_{3}$ & $\mathrm{SO}_{2}$ & $\mathrm{NH}_{3}$ \\
\hline LOD (ppbv) & 0.008 & 0.059 & 0.034 & 0.065 & 0.060 & 0.030 \\
Aerosol phase & $\mathrm{F}^{-}$ & $\mathrm{Cl}^{-}$ & $\mathrm{NO}_{2}^{-}$ & $\mathrm{NO}_{3}^{-}$ & $\mathrm{SO}_{4}^{2-}$ & $\mathrm{NH}_{4}^{+}$ \\
LOD $\left(\mu \mathrm{g} \mathrm{m}^{-3}\right)$ & 0.008 & 0.043 & 0.023 & 0.034 & 0.159 & 0.030 \\
\hline
\end{tabular}
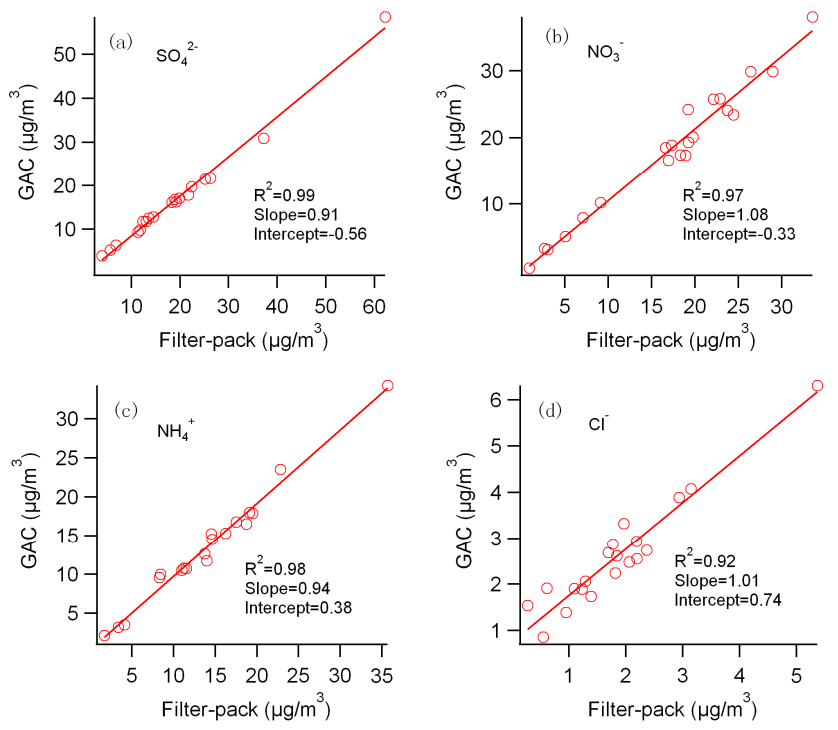

Fig. 7. Inter-comparison between the GAC-IC system and the filter measurement equipped with denuder and backup filters.

Figure 7 shows the inter-comparison results of sulfate, nitrate, chloride and ammonium between the GAC-IC system and the filter measurement. The inter-comparison of sulfate (Fig. 7a) shows the best correlation coefficient with $R^{2}$ as 0.99 and the slope as 0.91 , indicating stable and good performance of the GAC-IC system. Meanwhile, the results also proved that the GAC-IC system can perform well under high sulfate loadings as this experiment was conducted during period with a wide range of ambient sulfate concentration (from 0 to $60 \mu \mathrm{g} \mathrm{m}^{-3}$ ). As can be seen in Fig. $7 \mathrm{~b}$, $\mathrm{c}$ and d, good correlations between two methods are also found for nitrate $\left(R^{2}=0.97\right)$, ammonium $\left(R^{2}=0.98\right)$ and chloride $\left(R^{2}=0.92\right)$ with minor difference $(<10 \%)$. If just the first stage of filter-pack is considered (as we did in Kaiping study), the nitrate measurement by the GAC-IC system will be $40 \%$ higher than the filter measurement with $R^{2}$ as 0.68 (see Fig. 8a), suggesting the evaporation of particulate nitrate under high temperature. This evaporation loss is even worse and more serious for chloride (Fig. 8c). However, this difference is minor for ammonium $(<5 \%)$ because ammonium is primarily present in the form of $\left(\mathrm{NH}_{4}\right)_{2} \mathrm{SO}_{4}$, which is not evaporated (Fig. 8b). In summary, from the inter-comparison between the two methods, the GAC-IC system can supply reliable particulate sulfate, nitrate, chloride, and ammonium data in field measurement with a much wider range of ambient concentrations.

\section{Results and discussion}

\subsection{Field Measurements}

\subsubsection{Field campaign in Pearl River Delta (PRD)}

An intensive campaign supported by the Ministry of Science and Technology, China, was organized by Peking University in PRD from October to November 2008 (Huang et al., 2011). As part of this campaign, the GAC-IC system was applied in a rural site (Kaiping) for measuring gaseous and aerosol species and compared with other commercial instruments. The absorption solution was $\mathrm{Na}_{2} \mathrm{CO}_{3}(25 \mu \mathrm{M})$ in the GAC-IC system with a $\mathrm{PM}_{2.5}$ cyclone inlet installed on the roof of the site and a 3-m Teflon tube (protected by black material from sunlight) connecting the cyclone to the GAC sampler. Only anions were measured in the GAC and calibration was done by ionic standard mixture of $0.02,0.05$, $0.2,0.5$ and $1 \mathrm{ppm}$ once a week. The flow rate of the GAC sampler $\left(16.71 \mathrm{~min}^{-1}\right)$ was checked once a week. The GACIC system continuously measured $\mathrm{HCl}, \mathrm{HONO}, \mathrm{HNO}_{3}, \mathrm{SO}_{2}$, $\mathrm{SO}_{4}^{2-}, \mathrm{NO}_{3}^{-}$and $\mathrm{Cl}^{-}$with time resolution of $30 \mathrm{~min}$.

Usually, Teflon tube is not suitable for aerosol sampling because of the electrostatic charges; however, it is more convenient and applicable in field campaign in order to limit reactive gases wall losses. In this study, to minimize particles losses the cyclone was electrically grounded and the absorption solution was also conductive. In addition, the inlet was covered by black material to block the sunlight and prevent possible heterogeneous reactions.

$\mathrm{SO}_{2}$ concentration was also measured by online $\mathrm{SO}_{2}$ analyzer (43c, Thermo-Fisher, USA), which was calibrated by zero air and $\mathrm{SO}_{2}$ standard gas everyday. The measurement by the $43 \mathrm{c}$ is based on the absorption of ultraviolet (UV) light by $\mathrm{SO}_{2}$ molecules with a high time resolution of $10 \mathrm{~s}$ and Teflon tube as sampling inlet. A TEOM (1400, RP, USA) was used for $\mathrm{PM}_{2.5}$ mass concentration measurement.

Ambient HONO was continuously measured by a Long Path Absorption Photometer (LOPAP). The instrument was a modified version of the commercial LOPAP instrument (QUMA GmbH, Wuppertal). Detailed information about the instrument setup could be found in Li et al. (2012). During the campaign, the time resolution of the LOPAP HONO 

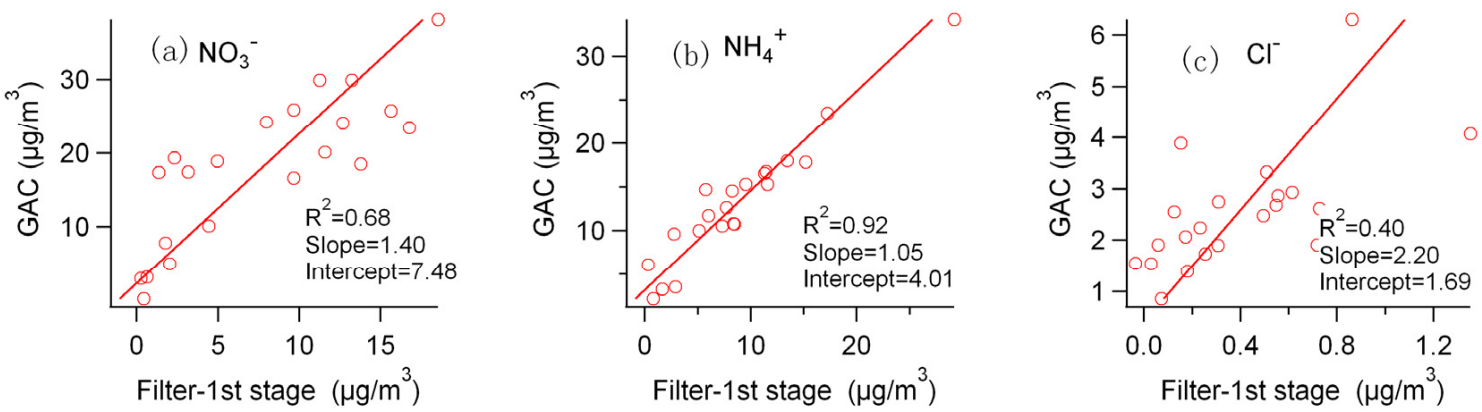

Fig. 8. Inter-comparison between the GAC-IC system and the filter measurement with data only from the 1st stage.

measurements was 4 min and no sampling inlet was applied for the system.

Teflon filters with a diameter of $47 \mathrm{~mm}$ (Whatman, UK) were installed in the filter sampler (Tianhong instruments, China) to collect $\mathrm{PM}_{2.5}$ samples twice a day from two periods (07:00 to 18:00 and 18:30 to 06:30). The exposed filters in Petri-dishes (Whatman, UK) were stored in a refrigerator at $4{ }^{\circ} \mathrm{C}$. The filters were extracted in $20.0 \mathrm{ml}$ of ultra pure water (18.2 M $\Omega$, Millipore, USA) in an ultrasonic bath for off-line analysis of water-soluble ions under the same chromatographic conditions as the GAC-IC system.

\subsubsection{Field comparison of aerosol species in Changdao}

Another intensive campaign was conducted in Changdao, a small island town located in the Bohai Sea, where a GAC-IC system and an Aerodyne High-Resolution Timeof-Flight Aerosol Mass Spectrometer (HR-ToF-AMS) were placed side by side for comparison purpose from 20 March to 26 April 2011. Pure water was used as absorption solution in this campaign for the low background of $\mathrm{SO}_{2}$ concentration in Changdao with cut size of $\mathrm{PM}_{2.5}$ cyclone and a 3-m Teflon tube (protected by black material from sunlight) connected on the roof. Because of the application of a cation chromatography in this campaign, $\mathrm{NH}_{3}$ and $\mathrm{NH}_{4}^{+}$were also measured besides the anion species with the same routine calibration conducted in Kaiping site.

The description of HR-ToF-AMS is available in previous publications (DeCarlo et al., 2006; Timonen et al., 2010; Huang et al., 2011). A $\mathrm{PM}_{1}$ cyclone was used as the AMS inlet to remove coarse particles and introduced sampled air into the instrument through a copper tube with a flow rate of $101 \mathrm{~min}^{-1}$ and the AMS sampled isokinetically from the center of the copper tube at a flow rate of $80 \mathrm{ml} \mathrm{min}^{-1}$. The time resolution of AMS was $4 \mathrm{~min}$. The operation conditions, detection mode and data processing of the AMS were same as those introduced by Huang et al. (2011). The parameter of collection efficiency (CE) of 0.5 was applied since the sampled air was dried through a Nafion (MD-110, Perma Pure, USA) (Takegawa et al., 2009).

\subsection{Overview of the GAC-IC performance in Kaiping site}

During the period from 20 October to 14 November 2008, the time series and diurnal variations of major species measured by the GAC-IC and $\mathrm{PM}_{2.5}$ mass by the TEOM are shown in Fig. 9. Statistical information of all results from the GAC-IC is summarized in Table 2.

The most abundant aerosol species at the site were $\mathrm{SO}_{4}^{2-}$ and $\mathrm{NO}_{3}^{-}$with average concentration as $12.4 \mu \mathrm{g} \mathrm{m}^{-3}$ and $4.6 \mu \mathrm{g} \mathrm{m}^{-3}$ and accounting for $20.4 \%$ and $6.2 \%$ of $\mathrm{PM}_{2.5}$ mass concentration, respectively. Though $\mathrm{Cl}^{-}$was not enriched in fine particles, it showed similar variations with $\mathrm{NO}_{3}^{-}$and sometimes could account for up to $9 \%$ of $\mathrm{PM}_{2.5}$ mass concentration (Fig. 9a and Table 2). Good correlation $\left(R^{2}\right.$ as 0.85$)$ was found between the sum of $\mathrm{SO}_{4}^{2-}, \mathrm{NO}_{3}^{-}$, $\mathrm{Cl}^{-}$and $\mathrm{NH}_{4}^{+}$-pre (predicted by the Eq. 1 ) and $\mathrm{PM}_{2.5}$ mass measured by TEOM (Fig. 9c and g). About $43 \%$ of total aerosol mass in $\mathrm{PM}_{2.5}$ was water-soluble ions, which agreed with previous findings in this area (Hagler et al., 2006; Lai et al., 2007). From the time series in Fig. 9, it can be seen that there were two major episodes (one from 25 to $27 \mathrm{Oc}$ tober the other from 5 to 6 November) for both aerosol and gaseous species.

$$
\begin{aligned}
\operatorname{Mass}\left(\mathrm{NH}_{4}^{+}-\text {pre }\right) & =\left[\frac{\operatorname{Mass}\left(\mathrm{SO}_{4}^{2-}\right) \times 2}{96}+\frac{\operatorname{Mass}\left(\mathrm{NO}_{3}^{-}\right)}{62}\right. \\
& \left.+\frac{\operatorname{Mass}\left(\mathrm{Cl}^{-}\right)}{35.5}\right] \times 18
\end{aligned}
$$

Most of acidic gases exhibited same daily variation during the study period. A wide range of $\mathrm{SO}_{2}$ concentration from 0.26 to $43 \mathrm{ppb}$ was observed with a mean concentration of about $11.47 \mathrm{ppb}$, whereas the maximum concentration of other gases was all below $5.5 \mathrm{ppb}$ including HONO whose concentration was much lower than other studies in China as well (Su et al., 2008a, b; Qin et al., 2009).

Distinct diurnal variations for $\mathrm{NO}_{3}^{-}$and $\mathrm{Cl}^{-}$with the highest concentration in the morning (about 06:00) and the lowest (about 15:00) in the afternoon were observed. However, gaseous $\mathrm{HNO}_{3}$ and $\mathrm{HCl}$ exhibited reversed diurnal pattern, indicating that they were mainly produced by the evaporation 

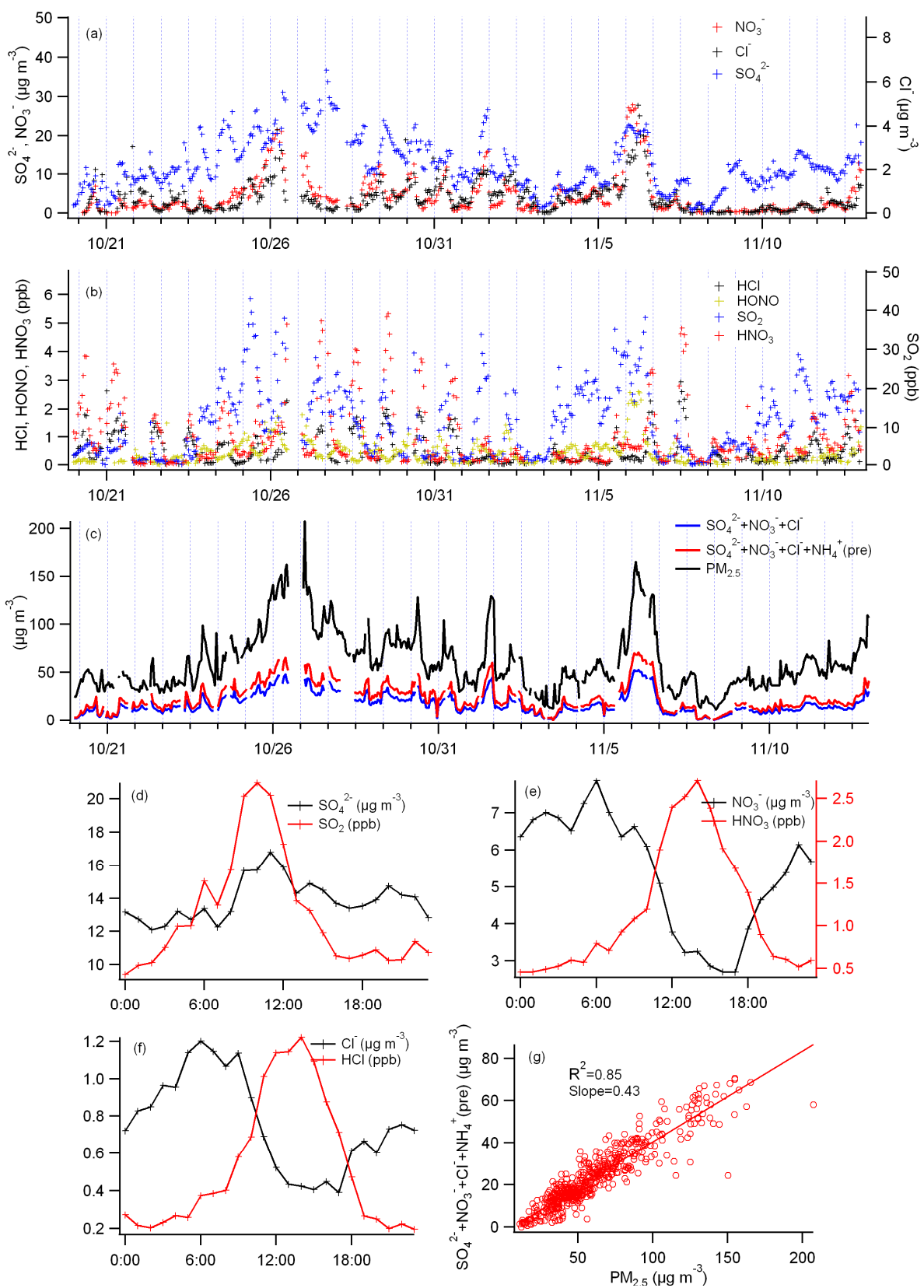

Fig. 9. The time series of (a) $\mathrm{SO}_{4}^{2-}, \mathrm{NO}_{3}^{-}$and $\mathrm{Cl}^{-}$; (b) gaseous $\mathrm{HCl}, \mathrm{HONO}, \mathrm{HNO}_{3}$ and $\mathrm{SO}_{2} ;(\mathbf{c}) \mathrm{SO}_{4}^{2-}+\mathrm{NO}_{3}^{-}+\mathrm{Cl}^{-}, \mathrm{SO}_{4}^{2-}+\mathrm{NO}_{3}^{-}+\mathrm{Cl}^{-}$ $+\mathrm{NH}_{4}^{+}$(pre) and $\mathrm{PM}_{2.5}$; the diurnal variation of (d) $\mathrm{SO}_{4}^{2-}$ and $\mathrm{SO}_{2}$; (e) $\mathrm{NO}_{3}^{-}$and gaseous $\mathrm{HNO}_{3}$; (f) $\mathrm{Cl}^{-}$and gaseous $\mathrm{HCl}$; the agreement between (g) $\mathrm{SO}_{4}^{2-}+\mathrm{NO}_{3}^{-}+\mathrm{Cl}^{-}+\mathrm{NH}_{4}^{+}$(pre) and $\mathrm{PM}_{2.5}$.

Table 2. The statistics of major species measured by the GAC-IC system and $\mathrm{PM}_{2.5}$ by the TEOM (hourly average).

\begin{tabular}{|c|c|c|c|c|c|c|c|c|c|c|c|}
\hline & $\mathrm{HCl}$ & HONO & $\mathrm{HNO}_{3}$ & $\mathrm{SO}_{2}$ & $\mathrm{Cl}^{-}$ & $\mathrm{NO}_{3}^{-}$ & $\mathrm{SO}_{4}^{2-}$ & $\mathrm{PM}_{2.5}$ & $\mathrm{Cl}^{-} / \mathrm{PM}_{2.5}$ & $\mathrm{NO}_{3}^{-} / \mathrm{PM}_{2.5}$ & $\mathrm{SO}_{4}^{2-} / \mathrm{PM}_{2.5}$ \\
\hline & \multicolumn{4}{|c|}{ (ppb) } & \multicolumn{4}{|c|}{$\left(\mu \mathrm{g} \mathrm{m}^{-3}\right)$} & \multicolumn{3}{|c|}{$(\%)$} \\
\hline Mean & 0.55 & 0.48 & 1.07 & 11.47 & 0.76 & 4.57 & 12.37 & 62.22 & 1.22 & 6.16 & 20.38 \\
\hline Max. & 2.95 & 2.61 & 5.33 & 43.00 & 4.95 & 27.82 & 36.62 & 207.44 & 9.02 & 20.05 & 38.12 \\
\hline Min. & 0.05 & 0.02 & 0.04 & 0.26 & 0.03 & 0.03 & 0.47 & 11.17 & 0.08 & 0.19 & 2.91 \\
\hline
\end{tabular}




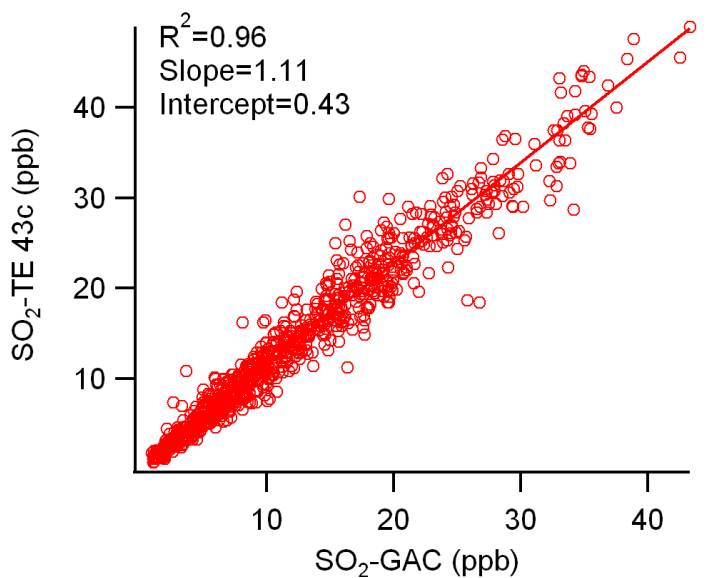

Fig. 10. Correlations of $\mathrm{SO}_{2}$ measurement by the GAC-IC system and the TE $43 \mathrm{c}$ analyzer.

of nitrate and chloride. $\mathrm{SO}_{2}$ and $\mathrm{SO}_{4}^{2-}$ showed the same diurnal variation and peaked around 10:00, which were probably transported from urban area.

Generally, as a semi-continuous method, the GAC-IC system showed good condition during the campaign and the reasonable variations of abundant species indicated that the instrument could be applied in field campaigns for long-term observation. The newly designed aerosol collector could measure water soluble ions as high as $70 \mu \mathrm{g} \mathrm{m}^{-3}$, which is particularly useful for highly polluted areas such as some major cities in China.

Several inter-comparisons between the GAC-IC and relevant instruments are introduced in Sect. 3.3 to validate the reliability of GAC-IC measurement. Because of the lack of instruments to measure $\mathrm{HNO}_{3}$ and $\mathrm{HCl}$ in this study, we only discuss the validation of the GAC-IC measurements for $\mathrm{HNO}_{3}$ and $\mathrm{HCl}$ as follows: (1) the collection efficiency of the two species by the WAD seems reliable (stated in Sect. 2.2.1); (2) these species can be precisely detected by the IC; (3) the spatial and diurnal variations of these two species are reasonable compared with nitrate and chloride. Thus in this study we consider the $\mathrm{HNO}_{3}$ and $\mathrm{HCl}$ results as semi quantitative at this point and future work will include the inter-comparison results of $\mathrm{HNO}_{3}$ and $\mathrm{HCl}$ when instruments are available.

3.3 Inter-comparisons of the GAC-IC with other relevant commercial instruments in field measurements

\subsubsection{Comparison of $\mathrm{SO}_{2}$ measurement between GAC-IC and TE 43c}

The data from the TE $43 \mathrm{c}$ was averaged to $30 \mathrm{~min}$ in order to compare with the data from the GAC-IC (30-min time resolution). Figure 10 presents the comparison of $\mathrm{SO}_{2}$ measurements between two methods based on a large dataset
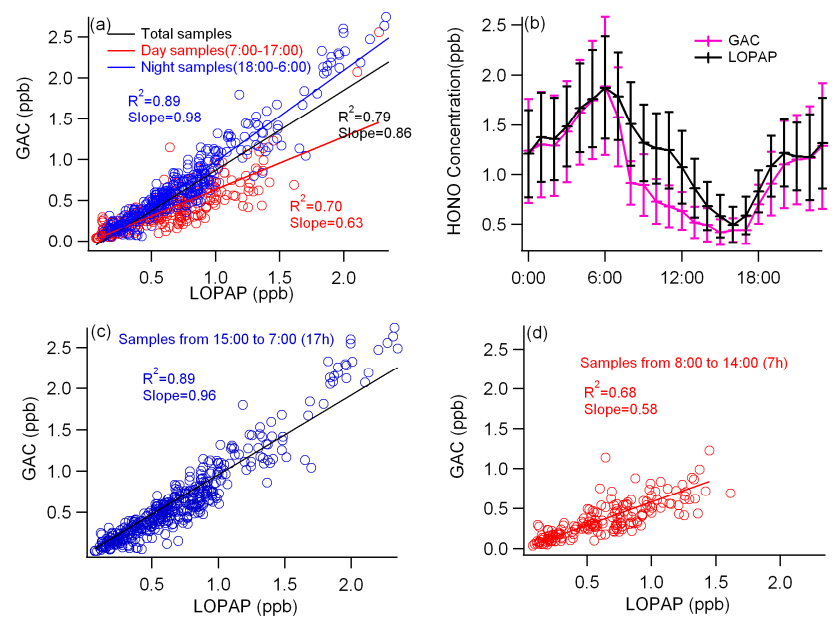

Fig. 11. The inter-comparison between the GAC-IC and the LOPAP: (a) inter-comparison of day samples from 07:00 to 17:00 $(11 \mathrm{~h})$ and night samples from 18:00 to 06:00 (13h); (b) diurnal variations of GAC-IC and LOPAP measurement; (c) intercomparison of samples from 15:00 to 07:00 (17 h); (d) intercomparison of samples from 08:00 to 14:00 (7 h).

( $N=1010$ ) over 24 days from 20 October to 13 November 2008 in the PRD campaign.

The results from two instruments agreed well with a satisfying correlation coefficient $\left(R^{2}\right.$ as 0.96$)$ and a small intercept of $0.43 \mathrm{ppb}$ though the measurement by the GACIC system was about $11 \%$ lower than that of the $\mathrm{SO}_{2}$ analyzer. Those results were consistent with those obtained by MARGA (a commercial version of SJAC instrument, Metrohm, Switzerland) in Finland (Makkonen et al., 2012). The high correlation indicated that the WAD used in the GAC sampler performed stable collection ability for $\mathrm{SO}_{2}$ from a range of 11.5 to $43 \mathrm{ppb}$, which prohibited the GAC-IC giving the higher sulfate value at high $\mathrm{SO}_{2}$ concentration $(>30 \mathrm{ppb})$ (Wu and Wang, 2007).

\subsubsection{Comparison of HONO measurement between GAC-IC and LOPAP}

The data from the LOPAP was averaged to $30 \mathrm{~min}$ for comparison with the GAC-IC. Figure 11 presents the comparison of HONO measurements between the GAC-IC and the LOPAP based on a dataset $(N=450)$ over 17 days.

Figure 11a shows the inter-comparison between the two instruments by day (07:00 to 17:00, $\left.R^{2}=0.70\right)$ and night (18:00 to $\left.06: 00, R^{2}=0.89\right)$ with night time samples of the GAC-IC measurement close to the LOPAP. Based on diurnal variation of HONO as seen in Fig. 11b, good agreement between two instruments can be seen during the period of 15:00 to 07:00, then samples are grouped into a period with better agreement and a poorer one (Fig. 11c and d, 15:00 to 07:00 with $R^{2}$ as 0.89 and 08:00 to $14: 00 R^{2}$ as 0.68 ) instead of simply classifying into day and night samples as in 

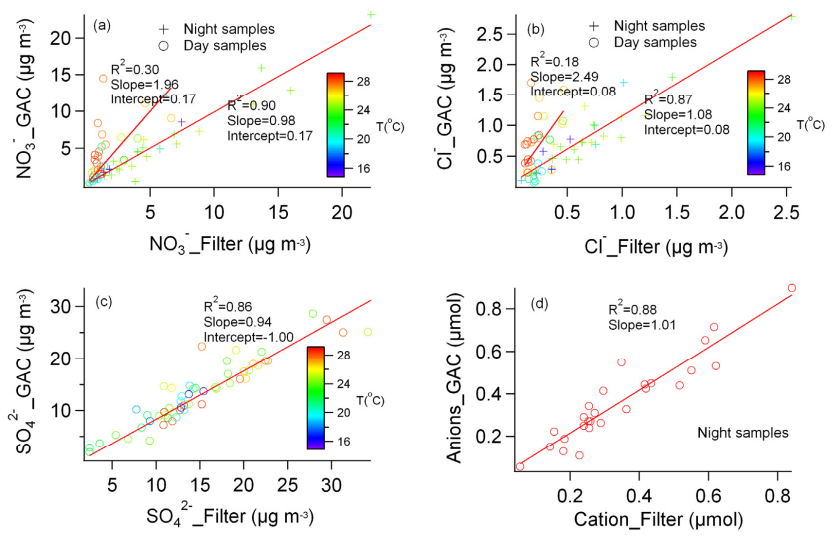

Fig. 12. Correlations of (a) $\mathrm{NO}_{3}^{-} ;$(b) $\mathrm{Cl}^{-}$and (c) $\mathrm{SO}_{4}^{2-}$ between the GAC-IC and filter measurement and (d) correlation between $2 \mathrm{SO}_{4}^{2-}+\mathrm{NO}_{3}^{-}+\mathrm{Cl}^{-}$measured by the GAC-IC system and $\mathrm{NH}_{4}^{+}$ of night samples measured by the filter.

Fig. 11a. We consider the HONO measurement by the GACIC comparable with the LOPAP from 15:00 to 07:00 (17 h) and uncertain between 08:00 to 14:00 (7 h).

At this time we do not have an exact explanation for the $42 \%$ lower measurement by the GAC-IC during the period from 08:00-14:00. Due to interference by $\mathrm{NO}_{2}, \mathrm{NO}, \mathrm{SO}_{2}$, PAN and so on which produce HONO through heterogeneous reactions at surface or in the solution, HONO measured by wet effluent denuder method is often higher than that by the LOPAP which has already been found in our previous studies and reported by other publications (Heland et al., 2001; Gutzwiller et al., 2002; Spindler et al., 2003; Genfa et al., 2003). It was indeed an unusual case of this study at Kaiping because the GAC-IC system performed well in general. However, the result by the GAC-IC was unexpectedly lower than the LOPAP for a specific period (08:00 to 14:00). Because of the low concentration at the sampling site, we have ever doubted that the standard curve (used for calibration in the IC) at lower concentration might contribute to the lower measurement by the GAC-IC at daytime. However, no obvious change appeared when standard curve was changed by removing the highest standard point. It is possible that some other heterogeneous reactions or interference by light happened on the GAC (indoor) and the LOPAP (outdoor) measurement from 08:00 to 14:00. In conclusion, reasons for such discrepancy remain unclear and will need to be determined in future research.

\subsubsection{Comparison between GAC-IC and filter sampler}

The comparisons of $\mathrm{SO}_{4}^{2-}, \mathrm{NO}_{3}^{-}$and $\mathrm{Cl}^{-}$between GACIC and filter sampler were made based on data $(N=55)$ of 28 days as shown in Fig. 12. The data from the GAC-IC system was averaged to the corresponding time period of the filter samples for comparison purpose.
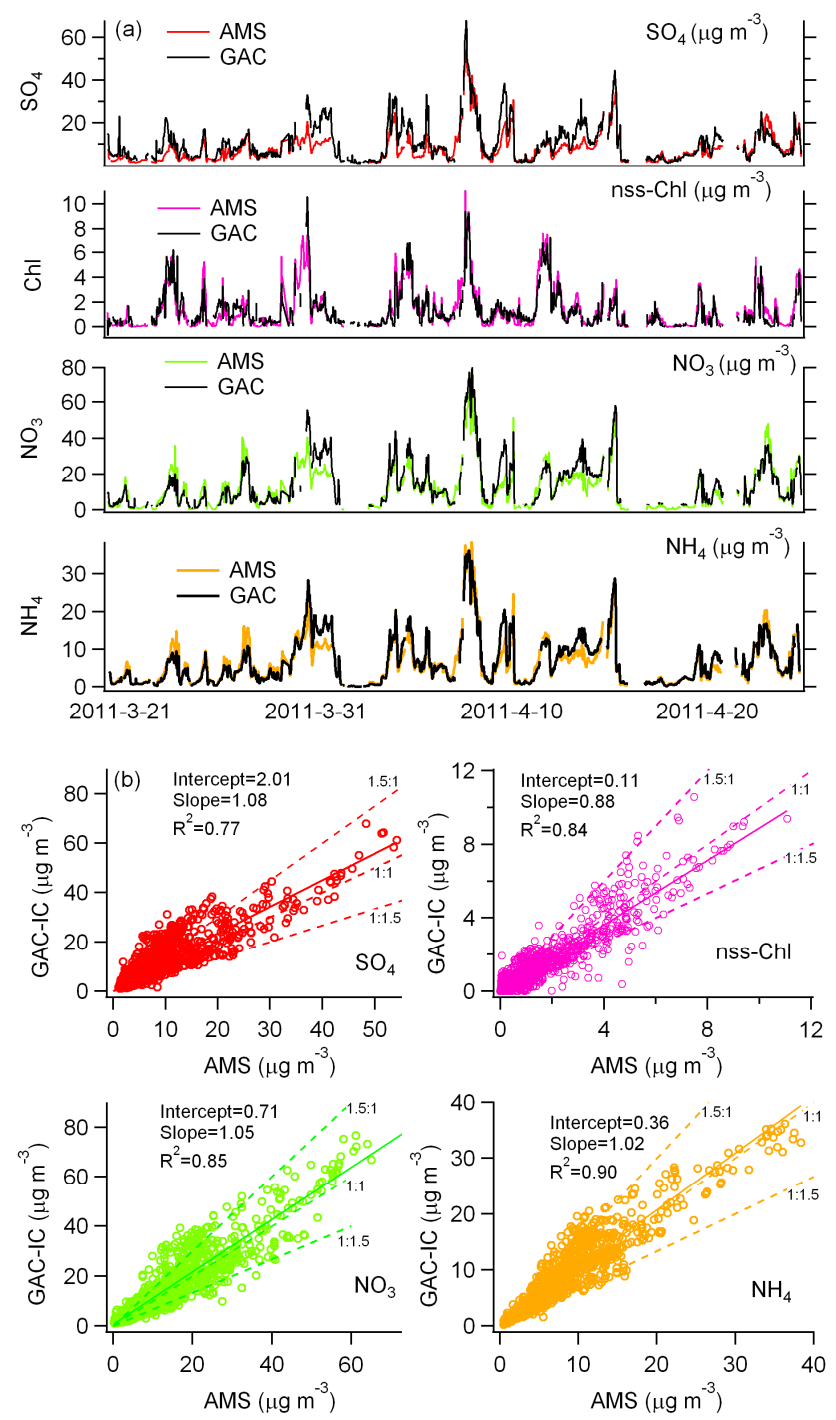

Fig. 13. Inter-comparisons between the GAC-IC system and the AMS. We use 30-min average data for the inter-comparisons. The solid lines represent the regression lines. The dashed lines indicate 1.5:1, $1: 1$ and $1: 1.5$ correspondence lines.

A better comparison of $\mathrm{SO}_{4}^{2-}$ was seen with $R^{2}$ as 0.86 , a slope of 0.94 and a small intercept (Fig. 12c). However, worse comparisons were seen for $\mathrm{NO}_{3}^{-}\left(R^{2}\right.$ as 0.66$)$ and $\mathrm{Cl}^{-}\left(R^{2}\right.$ as 0.50$)$ than the $\mathrm{SO}_{4}^{2-}$. The lower concentrations of $\mathrm{NO}_{3}^{-}$and $\mathrm{Cl}^{-}$by the filter method could be attributed to high air temperature which enhanced negative artifacts from the evaporation loss of chloride and nitrate during sampling. The ambient air temperature of Guangzhou ranged from 19 to $32{ }^{\circ} \mathrm{C}$ during our sampling period. As shown in Fig. 12a and $\mathrm{b}$, the evaporation loss becomes significant at temperature higher than $27^{\circ} \mathrm{C}$. To further investigate this problem, we grouped samples into day samples (sampled during the time from 07:00 to 18:00) and night samples (sampled from 18:30 to 06:30). Better correlations of $\mathrm{NO}_{3}^{-}$and $\mathrm{Cl}^{-}$could 

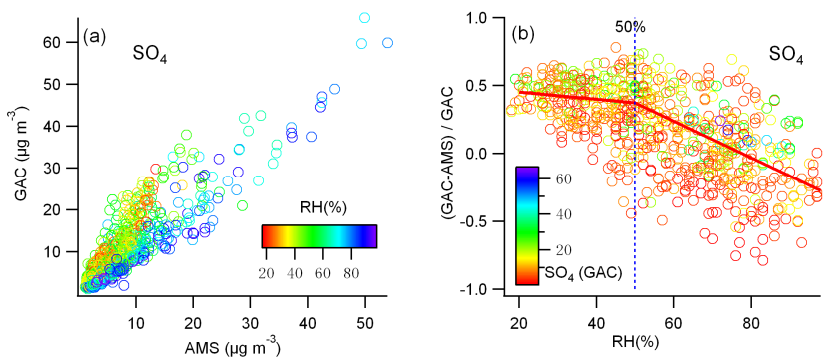

Fig. 14. Scatter plots of (a) the GAC-IC and the AMS for $\mathrm{SO}_{4}^{2-}$ measurement with color-coded according to the RH (1-h average data); (b) the relative difference of $\mathrm{SO}_{4}^{2-}$ measurement between the GAC-IC and the AMS versus the RH.

be seen for night samples with $R^{2}$ as 0.90 and 0.87 respectively. Poor correlations were found for day samples $\left(R^{2}\right.$ as 0.30 for $\mathrm{NO}_{3}^{-}$and 0.18 for $\mathrm{Cl}^{-}$). On average, our data suggested about $67 \%$ of $\mathrm{NO}_{3}^{-}$and $71 \%$ of $\mathrm{Cl}^{-}$might be lost due to sampling during daytime at higher temperature.

Because cations were not measured by the GAC-IC system, the molar number of $\mathrm{NH}_{4}^{+}$measured by the filter sampler (only night samples, $N=27$ ) was compared with total molar number of anions measured by the GAC-IC (Fig. 12d). High correlation $\left(R^{2}\right.$ as 0.88$)$ provided supportive evidence that aerosol species measured by the GAC-IC were reliable and a slope of 1.01 indicated that aerosol observed at the site was mainly neutral.

Excellent agreement of $\mathrm{SO}_{4}^{2-}$ between GAC-IC and filter measurements indicated that the newly designed aerosol collector had stable collection efficiency for $\mathrm{SO}_{4}^{2-}$ over a wide range of concentration in this campaign (from 0.47 to $36.6 \mu \mathrm{g} \mathrm{m}^{-3}$ ). About one fifth of the $\mathrm{SO}_{4}^{2-}$ data were higher than $20 \mu \mathrm{g} \mathrm{m}^{-3}$ where the GAC-IC results were still consistent with filter method. The problem of measurement going down at high concentration of $\mathrm{SO}_{4}^{2-}$ as reported by Wu and Wang (2007) was not found in this study which indicated that the GAC-IC system could perform well in aerosol study under high loadings of $\mathrm{SO}_{4}^{2-}$ and $\mathrm{SO}_{2}$. When day samples of filter measurement were excluded, much better agreements of $\mathrm{NO}_{3}^{-}$and $\mathrm{Cl}^{-}$were obtained even at the highest $\mathrm{NO}_{3}^{-}$concentration $\left(27.8 \mu \mathrm{g} \mathrm{m}^{-3}\right)$. As shown in Table 3, the good correlation between GAC-IC and filter method in this work was comparable with previous studies of other countries where the observed concentrations were much smaller (below 25 and $14 \mu \mathrm{g} \mathrm{m}^{-3}$ for $\mathrm{SO}_{4}^{2-}$ and $\mathrm{NO}_{3}^{-}$) than observed in China (Drewnick et al., 2003; Wittig et al., 2004; Homolya et al., 2005; Makkonen et al., 2012). Most (semi-)continuous measurements were found much lower than filter-based method and the better comparison results done in Beijing and Shanghai were just part of data used. However, in our study, measurements of the GAC-IC system agreed much better with measurements of filter-based method as can be seen by a slope of $0.94,0.98$ and 1.08 for $\mathrm{SO}_{4}^{2-}, \mathrm{NO}_{3}^{-}$and $\mathrm{Cl}^{-}$respec-
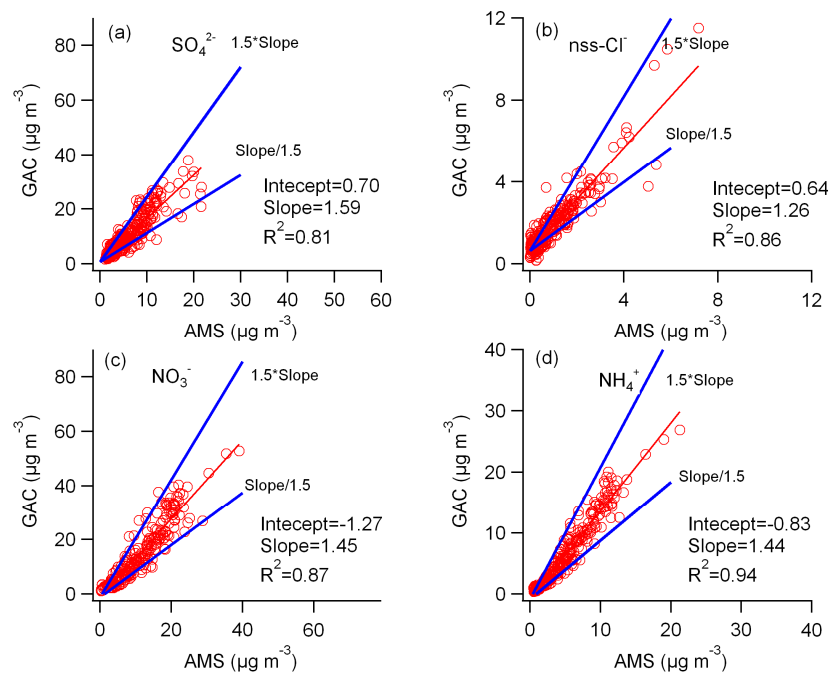

Fig. 15. Inter-comparisons between GAC-IC and AMS measured with $\mathrm{RH}$ below $50 \%$. We use 1-h average data for the intercomparisons.

tively over a larger range. In summary, the GAC-IC system could provide highly time-resolved and comparable $\mathrm{SO}_{4}^{2-}$ and $\mathrm{NO}_{3}^{-}$data and it was particularly applicable in highly polluted areas.

\subsubsection{Comparison between GAC-IC and AMS}

The species we used for comparison between the GAC-IC and AMS such as sulfate, nitrate and ammonium were enriched in $\mathrm{PM}_{1}$. Therefore, a direct comparison between these two instruments with different cutoff sizes was made in this study. Sea salt particles which can be easily captured and measured by the GAC-IC cannot be measured by the AMS (Takegawa et al., 2009). We estimated non-sea salt (nss) $\mathrm{Cl}^{-}$ based on the GAC-IC data assuming that all of the measured $\mathrm{Na}^{+}$was originated from sodium chloride $(\mathrm{NaCl})$ in sea salt. Figure 13 presents the comparison of $\mathrm{SO}_{4}^{2-}$, nss$\mathrm{Cl}^{-}, \mathrm{NO}_{3}^{-}$and $\mathrm{NH}_{4}^{+}$measurements (30-min time resolution) between two methods based on a large dataset $(N=1450)$ over 36 days from 20 Match to 24 April 2010, in Changdao campaign.

Both the AMS and the GAC-IC system could track the temporal variations of air pollutants and agreed well. For example, measurements of four ions in aerosol from two instruments exhibited good and positive correlations $\left(R^{2}\right.$ as $0.77,0.84,0.85$ and 0.90 for $\mathrm{SO}_{4}^{2-}, \mathrm{nss}_{-} \mathrm{Cl}^{-}, \mathrm{NO}_{3}^{-}$and $\mathrm{NH}_{4}^{+}$, respectively). The nss- $\mathrm{Cl}^{-}$concentration estimated above is lower than that AMS measured with a slope of 0.88. It was because $\mathrm{Cl}^{-}$from sea salt could be partially or fully depleted by reaction between $\mathrm{NaCl}$ and acid such as nitric acid $\left(\mathrm{HNO}_{3}\right)$. Though the different cut size of particle measured in this campaign, the results were much better than the correlations between PILS-IC and AMS with $R^{2}$ ranged from 
Table 3. Summary of inter-comparison results of semi-continuous instrument with filter-based method.

\begin{tabular}{|c|c|c|c|c|c|c|c|c|}
\hline Site & Instrument & Size & & Range & $R^{2}$ & Slope* & Intercept & Reference \\
\hline \multirow{3}{*}{ New York } & PILS & \multirow{3}{*}{$\mathrm{PM}_{2.5}$} & $\mathrm{SO}_{4}^{2-}$ & $0-25$ & 0.91 & 0.71 & 0.13 & \multirow{3}{*}{ Drewnick et al. (2003) } \\
\hline & R\&P 8400 & & $\mathrm{SO}_{4}^{2-}$ & $0-25$ & 0.95 & 0.73 & 0.34 & \\
\hline & HSHP & & $\mathrm{SO}_{4}^{2-}$ & $0-25$ & 0.92 & 0.68 & 0.63 & \\
\hline \multirow{2}{*}{ Pittsburg } & \multirow{2}{*}{$\mathrm{R} \& \mathrm{P} 8400$} & \multirow{2}{*}{$\mathrm{PM}_{2.5}$} & $\mathrm{SO}_{4}^{2-}$ & $0-25$ & 0.83 & 0.71 & 0.42 & \multirow{2}{*}{ Wittig et al. (2004) } \\
\hline & & & $\mathrm{NO}_{3}^{-}$ & $0-8$ & 0.89 & 0.78 & 0.20 & \\
\hline \multirow{2}{*}{ Seattle } & \multirow{10}{*}{ R\&P 8400} & \multirow{10}{*}{$\mathrm{PM}_{2.5}$} & $\mathrm{SO}_{4}^{2-}$ & $0.5-5$ & 0.89 & 1.22 & 0.28 & \\
\hline & & & $\mathrm{NO}_{3}^{-}$ & $0.2-5$ & 0.89 & 0.78 & 0.20 & \\
\hline Phoenix & & & $\mathrm{SO}_{4}^{2-}$ & - & - & - & - & \\
\hline Phoenix & & & $\mathrm{NO}_{3}^{-}$ & $0.2-15$ & 0.86 & 0.59 & 0.99 & \\
\hline \multirow{2}{*}{ Deer Park } & & & $\mathrm{SO}_{4}^{2-}$ & $1-6$ & 0.87 & 0.74 & 1.65 & \multirow[t]{2}{*}{ Homolya et al. (2005) } \\
\hline & & & $\mathrm{NO}_{3}^{-}$ & $0.2-2$ & 0.21 & 1.23 & 0.53 & \\
\hline \multirow{2}{*}{ Chicago } & & & $\mathrm{SO}_{4}^{2-}$ & $0.5-21$ & 0.84 & 0.47 & 0.99 & \\
\hline & & & $\mathrm{NO}_{3}^{-}$ & $0.2-14$ & 0.82 & 0.46 & 0.51 & \\
\hline \multirow{2}{*}{ Indianapolis } & & & $\mathrm{SO}_{4}^{2-}$ & $0.5-21$ & 0.83 & 0.59 & 0.99 & \\
\hline & & & $\mathrm{NO}_{3}^{-}$ & $0.2-12$ & 0.85 & 0.56 & 0.25 & \\
\hline \multirow{2}{*}{ Beijing** } & \multirow{2}{*}{ AIM (Commercialized SJAC) } & \multirow{2}{*}{$\mathrm{PM}_{2.5}$} & $\mathrm{SO}_{4}^{2-}$ & $<20$ & 0.94 & 0.97 & 0.60 & \multirow{2}{*}{ Wu and Wang. (2007) } \\
\hline & & & $\mathrm{NO}_{3}^{-}$ & $<15$ & 0.90 & 0.69 & -0.20 & \\
\hline \multirow{2}{*}{ Shanghai $* * *$} & \multirow{2}{*}{ AIM (Commercialized SJAC) } & \multirow{2}{*}{$\mathrm{PM}_{2.5}$} & $\mathrm{SO}_{4}^{2-}$ & $<20$ & 0.89 & 0.95 & 1.41 & \multirow{2}{*}{ Wu and Wang. (2007) } \\
\hline & & & $\mathrm{NO}_{3}^{-}$ & $<15$ & 0.86 & 0.89 & 0.03 & \\
\hline \multirow{2}{*}{ Finland } & \multirow{2}{*}{ MARGA (Commercialized SJAC) } & \multirow{2}{*}{$\mathrm{PM}_{10}$} & $\mathrm{SO}_{4}^{2-}$ & $<6$ & 0.98 & 0.84 & 0.24 & \multirow{2}{*}{ Makkonen et al. (2012) } \\
\hline & & & $\mathrm{NO}_{3}^{-}$ & $<6$ & 0.91 & 0.89 & 0.51 & \\
\hline \multirow{3}{*}{ Kaiping } & \multirow{3}{*}{ GAC } & \multirow{3}{*}{$\mathrm{PM}_{2.5}$} & $\mathrm{SO}_{4}^{2-}$ & $0-37$ & 0.86 & 0.94 & -1.00 & \multirow{3}{*}{ This study } \\
\hline & & & $\mathrm{NO}_{3}^{-}$ & $0-28$ & 0.90 & 0.98 & 0.17 & \\
\hline & & & $\mathrm{Cl}^{-}$ & $<5$ & 0.87 & 1.08 & 0.08 & \\
\hline
\end{tabular}

* Semi-continuous or continuous method $=$ Slope $\times$ filter method + Intercept. $* * \mathrm{SO}_{4}^{2-}$ data bigger than $20 \mu \mathrm{g} \mathrm{m}{ }^{-3}$ and $\mathrm{NO}_{3}^{-}$data bigger than $15 \mu \mathrm{\mu g} \mathrm{m}{ }^{-3}$ were omitted. $* * * \mathrm{SO}_{4}^{2-}$ data when daily top five $\mathrm{SO}_{2}$ concentrations more than $30 \mathrm{ppb}$ and $\mathrm{NO}_{3}^{-}$data bigger than $15 \mu \mathrm{g} \mathrm{m}{ }^{-3}$ were omitted.

0.59 to 0.86 for different species and both of which were deployed $\mathrm{PM}_{1}$ cyclones (Takegawa et al., 2009). For the major ions $\left(\mathrm{NO}_{3}^{-}\right.$and $\left.\mathrm{NH}_{4}^{+}\right)$, about $90 \%$ of the data points fell within areas between two regression lines (1.5:1 and 1:1.5, $50 \%$ range), and the linear regression slopes for $\mathrm{NO}_{3}^{-}$and $\mathrm{NH}_{4}^{+}$were 1.05 to 1.02 , respectively. It indicated that agreement between the AMS and GAC-IC during this period was $50 \%$ with respect to individual $30-\mathrm{min}$ data points. For sulfate, about $70 \%$ of the data points fell within this $50 \%$ range.

Though in general the data between the GAC-IC and the AMS was correlated well in Fig. 13, significant difference could be seen during some specific periods when the AMS $\left(\mathrm{PM}_{1}\right)$ measured even higher concentration than the GAC-IC $\left(\mathrm{PM}_{2.5}\right)$. The issue of collection efficiency (CE) influenced by relative humidity $(\mathrm{RH})$ is known and has been always considered in various studies. For example, Allan et al. (2004) have reported that the $\mathrm{CE}$ value depends on the $\mathrm{RH}$ of the sampled air, which can vary from 0.5 at low RH to 1 at high
RH. Takegawa et al. (2009) also applied a CE value as 1 under high RH. To minimize this impact, the nafion tube was applied as particle dryer in the inlet of AMS in our study. Whereas, a negative correlation is still found by the relative difference of GAC-IC and AMS versus RH (Fig. 14b) and AMS measurement tends to give higher values than GAC under higher RH environment (Fig. 14a), which means the drying efficiency of nafion tube is not well considered in the study on Changdao where the average $\mathrm{RH}$ was $55.5 \%$ during the sampling period with one tenth of time above $85 \%$ and maximum RH reaching $98 \%$.

As can be seen in Fig. 15, measurements by the GACIC system and AMS agree well when RH is below $50 \%$. A less scattered plot and higher $R^{2}$ are achieved compared to the results using all data with $\mathrm{RH}$ up to $98 \%$ (Fig. 13). The improved new $R^{2}$ from 0.81 to 0.94 and all data falling within the area between two regression lines with a slope of 
$1.5^{*}$ original slope and original slope 1.5 , respectively, suggest these species can be measured well by the GAC-IC.

\section{Conclusions}

Modifications and improvements have to be made in order to optimize the performance of some imported instruments in highly polluted urban areas such as some megacities in China. For this purpose, a Gas and Aerosol Collector (GAC) was developed basing on the original SJAC sampler in this study. With effective changes and improvements, the GAC sampler is not only simplified, but also more applicable than the SJAC in areas with high concentrations of air pollutants. The combination of the GAC with IC systems provides a powerful tool to carry out online field measurements and to simultaneously study chemical species in both gas and aerosol.

The GAC-IC system has been validated extensively both in the laboratory and the field. A dull-polished WAD was applied in the GAC sampler and a collection efficiency of $>98 \%$ was observed when using $\mathrm{Na}_{2} \mathrm{CO}_{3}(25 \mu \mathrm{M})$ as the absorption solution and this efficiency remained stable from 20 to $90 \mathrm{ppb}$ for $\mathrm{SO}_{2}$. It is suggested that a higher concentration of $\mathrm{Na}_{2} \mathrm{CO}_{3}$ solution should be applied if ambient $\mathrm{SO}_{2}$ concentration is higher than $90 \mathrm{ppb}$. The performance tests also showed that the penetrating ratio through the WAD was reasonable and a capture ratio higher than $99.5 \%$ for particulate sulfate was obtained by the newly designed aerosol collector. The measurements of particulate species by the GAC-IC system were compared with the traditional filter-pack method. Their results were highly correlated with $R^{2}$ as $0.99,0.97$, 0.98 and 0.92 for sulfate, nitrate, ammonium, and chloride, respectively, indicating good performance of the GAC-IC system for the above species in particulate matter.

Inter-comparison experiments were also performed in an intensive campaign in Guangzhou. A high correlation coefficients of 0.96 found for $\mathrm{SO}_{2}$ measurements between the GAC-IC system and TE $43 \mathrm{c}\left(\mathrm{SO}_{2}\right.$ analyzer), indicating a high performance of the GAC sampler. The GAC-IC measured comparable HONO with the LOPAP during the period of 15:00 to 07:00 (17 h, $R^{2}$ as 0.91); however the lower measurement by the GAC-IC between 08:00 to $14: 00\left(7 \mathrm{~h}, R^{2}\right.$ as 0.68 ) could not be explained temporally, which should be paid more attention in further study. Due to the lack of relevant instruments to measure $\mathrm{HNO}_{3}$ and $\mathrm{HCl}$, we consider measurements of these gases as semi quantitative in this study. The comparison between the GAC-IC system and filter samples clearly revealed the evaporation loss of chloride and nitrate by the traditional filter method especially for samples collected during the daytime, when about $70 \%$ of chloride and nitrate could be lost. For night samples, the agreements were rather good.

The developed GAC-IC system was also compared to AMS, a becoming widely used online instrument for aerosol, in a field campaign in Changdao close to Bohai Sea. The results between these two instruments agreed well with $R^{2}$ ranging from 0.77 to 0.90 for $\mathrm{SO}_{4}^{2-}$, nss-Cl ${ }^{-}, \mathrm{NO}_{3}^{-}$and $\mathrm{NH}_{4}^{+}$ respectively, which were improved from 0.81 to 0.94 when inter comparison was done with RH below $50 \%$.

In summary, the high correlations with $\mathrm{SO}_{2}$ and $\mathrm{SO}_{4}^{2-}$ in a wide range as well as good slopes of near one with filterbased method proved that the GAC-IC system performed stable collection efficiencies for both gas and aerosol under high loadings. The new system showed well condition in the intercomparisons with the TE 43c, LOPAP, filter-based method and AMS, and it had been improved in a way that the developed instrument can be easily operated and data are processed quickly. It will be a powerful tool in future intensive campaigns or long-term monitoring stations to study various environmental issues.

Acknowledgements. This work was supported by the " 863 " project (2006AA06A301) from the Ministry of Science and Technology of China, Special Funds for Scientific Research on Public Welfare (201009002) from Ministry of Environmental Protection of China and the National Natural Science Foundation of China (21025728). The authors would also like to thank Song Guo and Weiwei $\mathrm{Hu}$ for supplying important data for this paper. More thanks were given to Jingyue Tang and Qian Tang for carefully maintaining the instrument during the campaigns. The authors would like to show their appreciation to Theo Brauers and Rolf Häseler from IEK-8 Forschungszentrum Jülich for providing the LOPAP instrument and the corresponding technique support.

Edited by: S. C. Liu

\section{References}

Allan, J. D., Bower, K. N., Coe, H., Boudries, H., Jayne, J. T., Canagaratna, M. R., Millet, D. B., Goldstein, A. H., Quinn, P. K., Weber R. J., and Worsnop, D. R.: Submicron aerosol composition at Trinidad Head, CA during ITCT 2K2, its relationship with gas phase volatile organic carbon and assessment of instrument performance, J. Geophys. Res..-Atmos., 109, D23S24, doi:10.1029/2003JD004208, 2004.

Andreae, M. O., Schmid, O., Yang, H., Chand, D., Yu, J. Z., Zeng, L. M., and Zhang, Y. H.: Optical properties and chemical composition of the atmospheric aerosol in urban Guangzhou, China, Atmos. Environ., 42, 6335-6350, 2008.

Andrews, E., Saxena, P., Musarra, S., Hildemann, L. M., Koutrakis, P., McMurry, P. H., Olmez, I., and White, W. H.: Concentration and composition of atmospheric aerosols from the 1995 SEAVS experiment and a review of the closure between chemical and gravimetric measurements, J. Air Waste Manag. Assoc., 50, 648664, 2000.

Chow, J. C.: Measurement methods to determine compliance with ambient air quality standards for suspended particles, J. Air Waste Manag. Assoc., 45, 320-382, 1995.

Chow, J. C., Chen, L. W. A., Watson, J. G., Lowenthal, D. H., Magliano, K. A., Turkiewicz, K., and Lehrman, D. E.: PM 2.5 chemical composition and spatiotemporal variability during the 
California Regional $\mathrm{PM}_{10} / \mathrm{PM}_{2.5}$ Air Quality Study (CRPAQS), J. Geophys. Res., 111, D10S-D14S, 2006.

DeCarlo, P. F., Kimmel, J. R., Trimborn, A., Northway, M. J., Jayne, J. T., Aiken, A. C., Gonin, M., Fuhrer, K., Horvath, T., Docherty, K. S., Worsnop, D. R., and Jimenez, J. L.: Field-Deployable, High-Resolution, Time-of-Flight Aerosol Mass Spectrometer, Anal. Chem., 78, 8281-8289, 2006.

Drewnick, F., Schwab, J. J., Hogrefe, O., Peters, S., Husain, L., Diamond, D., Weber, R., and Demerjian, K. L.: Intercomparison and evaluation of four semi-continuous $\mathrm{PM}_{2.5}$ sulfate instruments, Atmos. Environ., 37, 3335-3350, 2003.

Genfa, Z., Slanina, S., Boring, C. B., Jongejan, P. A. C., and Dasgupta, K.: Continous wet denuder measurements of atmospheric nitric and nitrous acid during the 1999 Atlanta supersite, Atmos. Environ., 37, 1351-1364, 2003.

Gutzwiller, L., Arens, F., Baltensperger, U., Gäggeler, H. W., and Ammann, M.: Significance of Semivolatile diesel exhaust organics for secondary HONO formation, Environ. Sci. Technol., 36, 677-682, 2002.

Hagler, G. S. W., Bergin, M. H., Salmon, L. G., Yu, J. Z., Wan, E. C. H., Zheng, M., Zeng, L. M., Kiang, C. S., Zhang, Y. H., Lau, A. K. H., and Schauer, J. J.: Source areas and chemical composition of fine particulate matter in the Pearl River Delta region of China [J], Atmos. Environ, 40, 3802-3815, 2006.

Heland, J., Kleffmann, J., Kurtenbach, R., and Wiesen, P.: A new instrument to measure gaseous nitrous acid (HONO) in the atmosphere, Environ. Sci. Technol., 35, 3207-3212, 2001.

Hillamo, R., Allegrini, I., Sparapani, R., and Kerminen, V. M.: Mass size distributions and precursor gas concentrations of major inorganic ions in'Antarctic aerosol, Int. J. Environ. An. Ch., 71, 353-372, 1998.

Homolya, J., Taylor, S., Smiley, J., Anderson, D., Bohlin, M., Frost, J., Michel, E., and Pausel, S.: A Multi-Site Performance Comparison of Semi-Continuous Carbon, Nitrate and Sulfate Monitors, available at: http://www.epa.gov/ttnamti1/files/ ambient/pm25/workshop/atlanta/cont1.pdf (last access: 2 January 2012), 2005.

Hu, M., Zhou, F. M., Shao, K. S., Zhang, Y. H., Tang, X. Y., and Slanina, J.: Diurnal variations of aerosol chemical compositions and related gaseous pollutants in Beijing and Guangzhou, J. Environ. Sci. Heal. A, 37, 479-488, 2002.

Huang, X.-F., He, L.-Y., Hu, M., Canagaratna, M. R., Kroll, J. H., Ng, N. L., Zhang, Y.-H., Lin, Y., Xue, L., Sun, T.-L., Liu, X.-G., Shao, M., Jayne, J. T., and Worsnop, D. R.: Characterization of submicron aerosols at a rural site in Pearl River Delta of China using an Aerodyne High-Resolution Aerosol Mass Spectrometer, Atmos. Chem. Phys., 11, 1865-1877, doi:10.5194/acp-11-18652011, 2011.

Jayne, J. T., Leard, D. C., Zhang, X., Davidovits, P., Smith, K. A., Kolb, C. E., and Worsnop, D. R.: Development of an aerosol mass spectrometer for size and composition analysis of submicron particles, Aerosol Sci. Tech., 33, 49-70, 2000.

Keuken, M. P., Wayers-IJpelaan, A., Mols, J. J., Otjes, R. P., and Slanina, J.: The determination of ammonia in ambient air by an automated thermodenuder system, Atmos. Environ., 23, 2177$2185,1989$.

Khlystov, A., Wyers, G. P., and Slanina, J.: The steam-jet aerosol collector, Atmos. Environ., 29, 2229-2234, 1995.
Khoder, M. I.: Atmospheric conversion of sulfur dioxide to particulate sulfate and nitrogen dioxide to particulate nitrate and gaseous nitric acid in an urban area, Chemosphere, 49, 675-684, 2002.

Lai, S. C., Zou, S. C., Cao, J. J., Lee, S. C., and Ho, K. F.: Characterizing ionic species in $\mathrm{PM}_{2.5}$ and $\mathrm{PM}_{10}$ in four Pearl River Delta cities, south China, J. Environ. Sci., 19, 939-947, 2007.

Li, X., Brauers, T., Häseler, R., Bohn, B., Fuchs, H., Hofzumahaus, A., Holland, F., Lou, S., Lu, K. D., Rohrer, F., Hu, M., Zeng, L. M., Zhang, Y. H., Garland, R. M., Su, H., Nowak, A., Wiedensohler, A., Takegawa, N., Shao, M., and Wahner, A.: Exploring the atmospheric chemistry of nitrous acid (HONO) at a rural site in Southern China, Atmos. Chem. Phys., 12, 1497-1513, doi:10.5194/acp-12-1497-2012, 2012.

Makkonen, U., Virkkula, A., Mäntykenttä, J., Hakola, H., Keronen, P., Vakkari, V., and Aalto, P. P.: Semi-continuous gas and inorganic aerosol measurements at a Finnish urban site: comparisons with filters, nitrogen in aerosol and gas phases, and aerosol acidity, Atmos. Chem. Phys., 12, 5617-5631, doi:10.5194/acp-125617-2012, 2012.

Nie, W., Wang, T., Gao, X., Pathak, R.K., Wang, X., Gao, R., Zhang, Q., Yang, L., and Wang, W.: Comparison among filter-based, impactor-based and continuous techniques for measuring atmospheric fine sulfate and nitrate, Atmos. Environ., 44, 4396-4403, 2010.

Niessner, R. and Klockow, D.: A thermoanalytical approach to speciation of atmospheric strong acids, Int. J. Environ. An. Ch., 8, 163-175, 1980.

Qin, M., Xie, P., Su, H., Gu, J., Peng, F., Li, S., Zeng, L., Liu, J., Liu,W., and Zhang, Y.: An observational study of the $\mathrm{HONOeNO}_{2}$ coupling at an urban site in Guangzhou City, South China. Atmos. Environ., 43, 5731-5742, 2009.

Seinfeld, J. and Pandis, S.: Atmospheric chemistry and physics, Wiley-Interscience, New York, NY, USA, 2nd Edn., 2006

Simon, P. K. and Dasgupta, P. K.: Wet effluent denuder coupled liquid_ion chromatography systems annular and parallel plate denuders, Anal. Chem., 65, 1134-1139, 1993.

Slanina, J., Ten Brink, H. M., Otjes, R. P., Even, A., Jongejan, P., Khlystov, A., Waijers-Ijpelaan, A., Hu, M., and Lu, Y.: The continuous analysis of nitrate and ammonium in aerosols by the Steam Jet Aerosol Collector (SJAC): extension and validation of the methodology, Atmos. Environ., 35, 2319-2330, 2001.

Spindler, G., Hesper, J., Brüggemann, E., Dubois, R., Müller, Th., and Herrmann, H.: Wet annular denuder measurements of nitrous acid: laboratory study of the artefact reaction of $\mathrm{NO}_{2}$ with $\mathrm{S}(\mathrm{IV})$ in aqueous solution and comparison with field measurements, Atmos. Environ., 37, 2643-2662, 2003.

Stolzenburg, M. R. and Hering, S. V.: A new method for the automated measurement of atmospheric fine particle nitrate, Environ. Sci. Technol., 34, 907-914, 2000.

Su, H., Cheng, Y. F., Shao, M., Gao, D. F., Yu, Z. Y., Zeng, L. M., Slanina, J., Zhang, Y. H., and Wiedensohler, A.: Nitrous acid (HONO) and its daytime sources at a rural site during the 2004 PRIDE-PRD experiment in China, J. Geophys. Res.Atmos., 113, D14312, doi:10.1029/2007JD009060, 2008a.

Su, H., Cheng, Y. F., Cheng, P., Zhang, Y. H., Dong, S. F., Zeng, L. M., Wang, X. S., Slanina, J., Shao, M., and Wiedensohler, A.: Observation of nighttime nitrous acid (HONO) formation at a non-urban site during PRIDE-PRD2004 in China, Atmos. Environ., 42, 6219-6232, 2008b. 
Takegawa, N., Miyakawa, T., Kuwata, M., Kondo, Y., Zhao, Y., Han, S., Kita, K., Miyazaki, Y., Deng, Z., Xiao, R. Hu, M., van Pinxteren, D., Herrmann, H., Hofzumahaus, A., Holland, F., Wahner, A., Blake, D. R., Sugimoto, N., and Zhu, T.: Variability of submicron aerosol observed at a rural site in beijing in the summer of 2006, J. Geophys. Res, 114, D00G05, doi:10.1029/2008JD010857, 2009.

Timonen, H., Aurela, M., Carbone, S., Saarnio, K., Saarikoski, S., Mäkelä, T., Kulmala, M., Kerminen, V.-M., Worsnop, D. R., and Hillamo, R.: High time-resolution chemical characterization of the water-soluble fraction of ambient aerosols with PILS-TOC-IC and AMS, Atmos. Meas. Tech., 3, 1063-1074, doi:10.5194/amt-3-1063-2010, 2010.

Trebs, I., Meixner, F. X., Slanina, J., Otjes, R., Jongejan, P., and Andreae, M. O.: Real-time measurements of ammonia, acidic trace gases and water-soluble inorganic aerosol species at a rural site in the Amazon Basin, Atmos. Chem. Phys., 4, 967-987, doi:10.5194/acp-4-967-2004, 2004.

Vecera, Z. and Dasgupta, P. K.: Measurement of ambient nitrous acid and a reliable calibration source for gaseous nitrous acid, Environ. Sci. Technol., 25, 255-260, 1991.

Wang, Y., Zhuang, G., Zhang, X., Huang, K., Xu, C., Tang, A., Chen, J., and An, Z.: The ion chemistry, seasonal cycle, and sources of $\mathrm{PM}_{2.5}$ and TSP aerosol in Shanghai, Atmos. Environ., 40, 2935-2952, 2006.
Weber, R. J., Orsini, D., Daun, Y., Lee, Y. N., Klotz, P. J., and Brechtel, F.: A particle-into-liquid collector for rapid measurement of aerosol bulk chemical composition, Aerosol Sci. Tech., 35, 718727, 2001.

Weber, R. J., Orsini, D., Duan, Y., Baumann, K., Kiang, C. S., Chameides, W., Lee, Y. N., Brechtel, F., Klotz, P., Jongejan, P., Brink, H. T., Slanina, J., Boring, C. B., Genfa, Z., Dasgupta, P., Hering, S., Stolzenburg, M., Dutcher, D. D., Edgerton, E., Hartsell, B., Solomon, P., and Tanner, R.: Intercomparison of near real-time monitors of $\mathrm{PM}_{2.5}$ nitrate and sulfate at the U.S. Environmental Protection Agency Atlanta Supersite, J. Geophys. Res., 108, 8421, doi:10.1029/2001JD001220, 2003.

Wittig, A. E., Takahama, S., Khlystov, A. Y., Pandis, S. N., Hering, S., Kirby, B., and Davidson, C.: Semi-continuous $\mathrm{PM}_{2.5}$ inorganic composition measurements during the Pittsburgh Air Quality Study, Atmos. Environ., 34, 3201-3213, 2004.

$\mathrm{Wu}, \mathrm{W}$. S. and Wang, T.: On the performance of a semi-continuous $\mathrm{PM}_{2.5}$ sulphate and nitrate instrument under high loadings of particulate and sulphur dioxide, Atmos. Environ., 41, 54425451, 2007.

Yao, X., Chan, C. K., Fang, M., Cadle, S., Chan, T., Mulawa, P., He, $\mathrm{K}$., and Ye, B.: The water-soluble ionic composition of $\mathrm{PM}_{2.5}$ in Shanghai and Beijing, China, Atmos. Environ., 36, 4223-4234, 2002. 